\title{
Experimental Design of Photo-Fenton Reactions for the Treatment of Car Wash Wastewater Effluents by Response Surface Methodological Analysis
}

\author{
Maha A. Tony ${ }^{1,2}$ and Zeinab Bedri ${ }^{3}$ \\ ${ }^{1}$ Green Chemistry Centre of Excellence, Department of Chemistry, University of York, York YO10 5DD, UK \\ ${ }^{2}$ Basic Engineering Science Department, Faculty of Engineering, Minoufiya University, Shebin El Koum, Minoufiya 32511, Egypt \\ ${ }^{3}$ Centre for Water Resources Research, School of Architecture, Landscape and Civil Engineering, University College Dublin, \\ Newstead, Belfield, Dublin 4, Ireland
}

Correspondence should be addressed to Maha A. Tony; maha_tony1@yahoo.com

Received 2 May 2014; Revised 20 July 2014; Accepted 4 August 2014; Published 25 August 2014

Academic Editor: Huu Hao Ngo

Copyright (c) 2014 M. A. Tony and Z. Bedri. This is an open access article distributed under the Creative Commons Attribution License, which permits unrestricted use, distribution, and reproduction in any medium, provided the original work is properly cited.

\begin{abstract}
Establishing a treatment process for practical and economic disposal of car wash wastewater has become an urgent environmental concern. Photo-Fenton's process as one of the advanced oxidation processes is a potentially useful oxidation process in treating such wastewater. Lab-scale experiments with UV source, coupled with Fenton's reagent, showed that hydrocarbon oil is degradable through such a process. The feasibility of photo-Fenton's process to treat wastewater from a car wash is investigated in the present study. A factorial design based on the response surface methodology was applied to optimize the photo-Fenton oxidation process conditions using chemical oxygen demand (COD) reduction as the target parameter to optimize. The reagent $\left(\mathrm{Fe}^{2+}\right.$ and $\mathrm{H}_{2} \mathrm{O}_{2}$ concentration) and $\mathrm{pH}$ are used as the controlling factors to be optimized. Maximal COD reduction (91.7\%) was achieved when wastewater samples were treated at $\mathrm{pH} 3.5$ in the presence of hydrogen peroxide and iron in amounts of $403.9 \mathrm{and} 48.4 \mathrm{mg} / \mathrm{L}$, respectively.
\end{abstract}

\section{Introduction}

Car washing leads to disposal of large amounts of oily polluted water which results in potentially high levels of nutrients, metals, and hydrocarbons flowing into storm drains. The composition of pollutants found in car wash wastewater varies according to the way of washing, mechanical car washing or artificial high-pressure water washing, and the size and type of vehicle (e.g., small car, truck, commercial van, etc.). In some cases, car wash wastewater may also contain heavy metals $[1-3]$

Considering the large volume of wastewater generated from the car washing process, wastewater treatment coupled with recycling may possibly be an essential water quality measure. For instance, in the US, commercial car wash facilities either recycle or treat their wash water prior to discharge to the sanitary sewer system, so most storm water impacts from car washing are from residential car wash systems that discharge polluted wash water into the storm drain system [1]. Some countries, for example, Switzerland, Germany, and The Netherlands, no longer allow outdoor car washing away from car washing stations [4].

In Egypt, as well as in many countries worldwide, car wash activities within petrol stations and outdoor car washing are among those activities that pose an environmental threat to the main freshwater source, the river Nile, which is already subjected to untreated wastewater [5]. Consequently, there is a growing need for research particularly on the application of innovative technologies in the treatment of such kind of wastewater.

The development of novel treatment methods encompasses investigations of advanced oxidation processes (AOPs), which are characterized by the production of the hydroxyl radical $\left({ }^{\circ} \mathrm{OH}\right)$ as a primary oxidant [6]. Examples of 
TABLE 1: Properties of chemicals used in the study ${ }^{1}$.

\begin{tabular}{|c|c|c|c|c|}
\hline Compound & Molecular weight & Formula & Manufacturer & Purity \\
\hline Iron chloride tetrahydrate & 198.8 & $\mathrm{FeCl}_{2} \cdot 4 \mathrm{H}_{2} \mathrm{O}$ & Sigma-Aldrich & $98.0 \%$ \\
\hline Hydrogen peroxide & 134.01 & $\mathrm{H}_{2} \mathrm{O}_{2}$ & Sigma-Aldrich & $30 \mathrm{wt} \%$ \\
\hline Sulfuric acid & 98.08 & $\mathrm{H}_{2} \mathrm{SO}_{4}$ & Sigma-Aldrich & $97.0 \%$ \\
\hline
\end{tabular}

${ }^{1}$ Hydrogen peroxide solution with a stabilizer (dipicolinic acid (approximately $40 \mathrm{mg} / \mathrm{L}$ )).

AOPs include the use of hydrogen peroxide with ultraviolet light $\left(\mathrm{H}_{2} \mathrm{O}_{2} / \mathrm{UV}\right)$ to treat hazardous compounds [7], Fenton and photo-Fenton reagent $\left(\mathrm{H}_{2} \mathrm{O}_{2} / \mathrm{Fe}^{2+}\right)$ [8-10], semiconductor photocatalysis [11], and the sonolysis process using ultrasonic irradiation [12]. Among various AOPs, the Fenton reagent is one of the most effective methods for treating various industrial effluents including wastewater $[13,14]$ and oily wastewater [15]. Previous work by the authors has involved the application of Fenton and the photo-Fenton reagents for the treatment of water polluted with diesel oil emulsion $[10,16]$. Although Fenton reagent has been reported extensively in the literature, there is a scarcity of publications focusing on its use for the treatment of car wash wastewater.

The main aim of the present study is to explore the possibility of treating car washing water to an acceptable level that can be recycled and reused for the same application. The study is of both national and international importance as it targets two global water issues: water conservation and water pollution. The study outlines the application of the photo-Fenton process to the mineralization of car wash wastewater. The effect of the reaction operating conditions is investigated and the factors that control the Fenton reaction process $\left(\mathrm{Fe}^{2+}, \mathrm{H}_{2} \mathrm{O}_{2}\right.$, and $\left.\mathrm{pH}\right)$ are optimized. Furthermore, the experimental design of the study applies a wellestablished [17-19] statistical-based technique, commonly known as RSM (response surface methodology) [20], to explore optimum range of values of $\mathrm{Fe}^{2+}, \mathrm{H}_{2} \mathrm{O}_{2}$, and $\mathrm{pH}$ for the maximum COD removal.

Factors to control the Fenton reaction process are the amounts of $\mathrm{Fe}^{2+}$ and $\mathrm{H}_{2} \mathrm{O}_{2}$ and the working $\mathrm{pH}$. Optimizing such parameters plays a key role towards the achievement of the Fenton reaction. The experimental design using a statistical-based technique, commonly known as RSM (response surface methodology) [20], has been increasingly applied in many fields including wastewater treatment to study the optimization of the treatment process.

\section{Materials and Methods}

2.1. Car Wash Wastewater. Wastewater samples were collected from a car washing wastewater tank at a petrol station in the south of Egypt. The principal properties of the wastewater are $82 \mathrm{mg}-\mathrm{COD} / \mathrm{L}$, turbidity of $28.1 \mathrm{NTU}, \mathrm{pH} 8.2$, and suspended solids of $55 \mathrm{mg} / \mathrm{L}$.

2.2. Experimental Materials. $\mathrm{Fe}^{2+}$ in Fenton's reagent $\left(\mathrm{Fe}^{2+} / \mathrm{H}_{2} \mathrm{O}_{2}\right)$ is prepared by making a solution from $\mathrm{Fe}^{2+}$ salt. $\mathrm{H}_{2} \mathrm{O}_{2}$ was obtained in liquid $\left(30 \%\right.$ of $\mathrm{H}_{2} \mathrm{O}_{2}$, wt) from

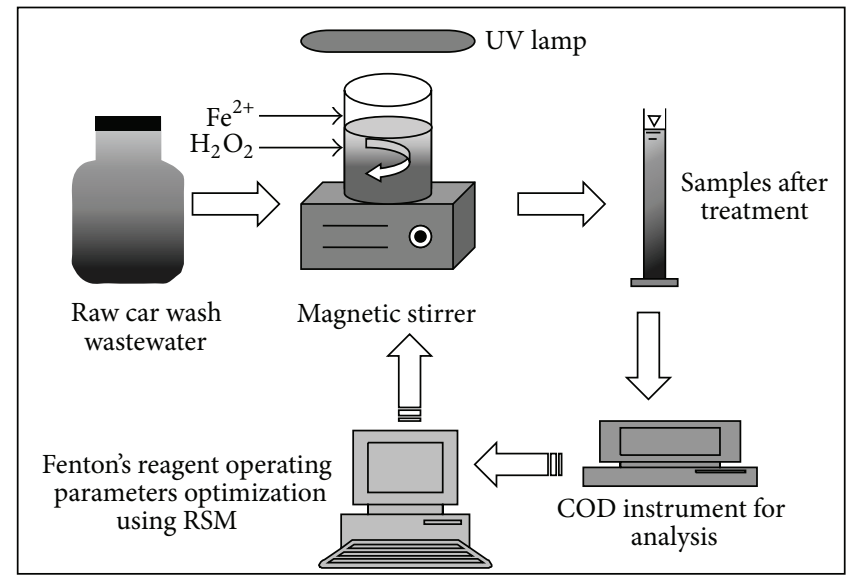

Figure 1: Schematic diagram of a lab-scale photo-Fenton test.

a commercial supplier. Sulfuric acid is used for adjusting the $\mathrm{pH}$ of the wastewater samples during treatment. Properties of chemicals used in this study are listed in Table 1.

2.3. Methodology. All photochemical experiments were carried out in a batch mode laboratory scale unit using a $250 \mathrm{~mL}$ beaker. Initially, the $\mathrm{pH}$ value of $100 \mathrm{~mL}$ of the car wash wastewater samples was adjusted at the desired values with sulfuric acid before being subjected to oxidation. Then, ferrous ions solution and hydrogen peroxide were added to produce hydroxyl radicals. Subsequently, the mixture was subjected to magnetic stirring and UV radiation $(254 \mathrm{~nm}$ wavelength), as illustrated in Figure 1. Samples were taken at regular time intervals in the discontinuous experiments and analyzed.

2.4. Analytical Determinations. The COD measurements were performed using $\mathrm{HACH}$ analyser (model $\mathrm{HACH}$ DR-2400). Turbidity was undertaken using a HACH $2100 \mathrm{~N}$ IS Turbidity meter (ISO method 7027). The $\mathrm{pH}$ of the wastewater was adjusted using a digital $\mathrm{pH}$-meter (model PHM62 Radiometer).

2.5. Experimental Design. The Fenton oxidation process was optimized by applying the response surface methodology [20]. COD removal, defined by (1), of the effluents was used as the variable to be optimized. The amounts of $\mathrm{H}_{2} \mathrm{O}_{2}, \mathrm{Fe}^{2+}$, and $\mathrm{pH}$ were chosen as the control factors to be optimized. 
TABLE 2: Range and levels of natural and corresponding coded variables for RSM.

\begin{tabular}{lccccc}
\hline \multirow{2}{*}{ Variable } & \multicolumn{2}{c}{ Symbols } & & \multicolumn{2}{c}{ Range and levels } \\
& Natural & Coded & -1 & 0 & 0 \\
\hline $\mathrm{Fe}^{2+}(\mathrm{mg} / \mathrm{L})$ & $\delta_{1}$ & $x_{1}$ & 30 & 40 & 50 \\
$\mathrm{H}_{2} \mathrm{O}_{2}(\mathrm{mg} / \mathrm{L})$ & $\delta_{2}$ & $x_{2}$ & 350 & 400 & 450 \\
$\mathrm{pH}$ & $\delta_{3}$ & $x_{3}$ & 3.5 & 6.5 \\
\hline
\end{tabular}

TABLE 3: RSM for the three experimental variables in coded units and corresponding natural values.

\begin{tabular}{|c|c|c|c|c|c|c|}
\hline \multirow{2}{*}{ Experiment number } & \multicolumn{3}{|c|}{ Natural variable } & \multicolumn{3}{|c|}{ Coded variable } \\
\hline & $\mathrm{Fe}^{2+}(\mathrm{mg} / \mathrm{L})$ & $\mathrm{H}_{2} \mathrm{O}_{2}(\mathrm{mg} / \mathrm{L})$ & $\mathrm{pH}$ & $x_{1}$ & $x_{2}$ & $x_{3}$ \\
\hline 1 & 30 & 350 & 6 & -1 & -1 & 0 \\
\hline 2 & 30 & 450 & 6 & -1 & 1 & 0 \\
\hline 3 & 50 & 350 & 6 & 1 & -1 & 0 \\
\hline 4 & 50 & 450 & 6 & 1 & 1 & 0 \\
\hline 5 & 40 & 350 & 3.5 & 0 & -1 & -1 \\
\hline 6 & 40 & 350 & 8.5 & 0 & -1 & 1 \\
\hline 7 & 40 & 450 & 3.5 & 0 & 1 & -1 \\
\hline 8 & 40 & 450 & 8.5 & 0 & 1 & 1 \\
\hline 9 & 30 & 400 & 3.5 & -1 & 0 & -1 \\
\hline 10 & 50 & 400 & 3.5 & 1 & 0 & -1 \\
\hline 11 & 30 & 400 & 8.5 & -1 & 0 & 1 \\
\hline 12 & 50 & 400 & 8.5 & 1 & 0 & 1 \\
\hline 13 & 40 & 400 & 6 & 0 & 0 & 0 \\
\hline 14 & 40 & 400 & 6 & 0 & 0 & 0 \\
\hline 15 & 40 & 400 & 6 & 0 & 0 & 0 \\
\hline
\end{tabular}

The initial design involved 15 tests, based on a three-level BoxBehnken factorial design [20]:

$$
\eta(\%)=\frac{\mathrm{COD}_{o}-\mathrm{COD}}{\mathrm{COD}_{o}} \times 100,
$$

where $\eta$ is the percentage of COD removal; $\mathrm{COD}_{o}$ measured COD in supernatant before oxidation $\left(\mathrm{mg}-\mathrm{O}_{2} / \mathrm{L}\right)$; and COD is the COD value after the treatment.

The first step in the RSM is to find a suitable approximation for the true functional relationship between the response $(\eta)$ and the set of independent variables. The following response function was used to correlate the dependent and independent variables in the response surface:

$$
\eta=\beta_{o}+\sum_{i=1}^{3} \beta_{i} X_{i}+\sum_{i=1}^{3} \beta_{i i} X_{i}^{2}+\sum_{i} \sum_{j=i+1} \beta_{i j} X_{i} X_{j},
$$

where $\eta$ is the predicted response; $i=1,2,3$ and $j=$ $1,2,3 ; \beta_{o}$ is the constant coefficient (intercept); $\beta_{i}$ are the linear coefficients; $\beta_{i j}$ are the cross product coefficients; and $X_{i}$ is the input controlling coded variable. In addition, the natural variables of the operating system $\left(\xi_{i}\right)$ were transferred to coded variables $\left(X_{i}\right)$ according to (3) [20] to simplify the model calculations. The results of COD removal and the turbidity were analysed through the statistical analysis software package of SAS Institute, Inc., [17] by performing the analysis of variance (ANOVA) and fitted with a secondorder polynomial model:

$$
x_{i}=\frac{\left(\delta_{i}\right)-(\text { its upper level }+ \text { its lower level }) / 2}{(\text { its upper level }- \text { its lower level }) / 2} .
$$

The combined effect of the three independent variables, that is, $\mathrm{Fe}^{+2}$ concentration, $\mathrm{H}_{2} \mathrm{O}_{2}$ concentration, and initial $\mathrm{pH}$, is represented as $\delta_{1}, \delta_{2}$, and $\delta_{3}$, respectively. The range of the experimental variables investigated in the study and the time of reaction ( $1 \mathrm{hr}$ ) were chosen according to preliminary tests. Therefore, each variable ranged between -1 and 1 , as the lower and upper levels, respectively. These ranges and levels are presented in Table 2. Fifteen runs were required for a complete set of the experimental designs.

\section{Results and Discussions}

3.1. Model Fitting. The three-level experiments were carried out according to the Box-Behnken design and the experimental plan is shown in Table 3 as coded and natural levels. The data shows the results of the photo-Fenton experiments as an average of three duplicate experimental results at each 
TABLE 4: Experimental and predicted achieved removal responses for RSM.

\begin{tabular}{lcc}
\hline \multirow{2}{*}{ Experiment number } & \multicolumn{2}{c}{$\eta(\%)$} \\
& Experimental results & Predicted response \\
\hline 1 & 68 & 72 \\
2 & 88 & 84 \\
3 & 93 & 96 \\
4 & 90 & 86 \\
5 & 98 & 90 \\
6 & 71 & 71 \\
7 & 88 & 88 \\
8 & 68 & 76 \\
9 & 84 & 88 \\
10 & 98 & 102 \\
11 & 78 & 74 \\
12 & 89 & 85 \\
13 & 29 & 29 \\
14 & 31 & 29 \\
15 & 28 & 29 \\
\hline
\end{tabular}

operating condition. The following is the second-order fitting polynomial equation of coded factors:

$$
\begin{aligned}
\eta(\%)= & 29.30+6.48 X_{1}+0.60 X_{2}-7.70 X_{3}+30.86 X_{1}^{2} \\
& -5.50 X_{1} X_{2}-0.75 X_{1} X_{3}+24.63 X_{2}^{2}+1.85 X_{2} X_{3} \\
& +27.18 X_{3}^{2} .
\end{aligned}
$$

The values of COD of the car washes wastewater as the responses obtained from the experiments and the predicted values are shown in Table 4 and plotted in Figure 2. A satisfactory agreement between the experimental and predicted data is achieved (Table 4). This is confirmed in Figure 2 which shows a regression coefficient $R^{2}$ value of 0.97 (the model being rejected if the $R^{2}$ value is less than 0.8 [20]). Thus, it is reasonable to state that the polynomial model (2) is a reliable tool to describe the Fenton reaction behaviour in car washing wastewater treatment.

3.2. Statistical Analysis. The effect of a certain factor is the change in response produced by the change in the level of that factor. When the effect of a factor depends on the level of another factor, the two factors are said to be interacting. In order to further assess the polynomial model (4) taking into account the interaction of factors, statistical analysis of variance (ANOVA) using SAS software was conducted and the statistical significance of the factors towards the response $(\eta)$ of the process was determined by Fisher's $F$-test $(F$-value is the ratio of mean square of regression to the mean square of the error) $[17,20]$. Student's $t$-test was used to determine the significance of the regression coefficients of the parameters. The probability values ( $P$ values) were used as a tool to check the significance of the model. In general, if the significance probability value $(P>F)$ is small (below 0.05$)$ and the

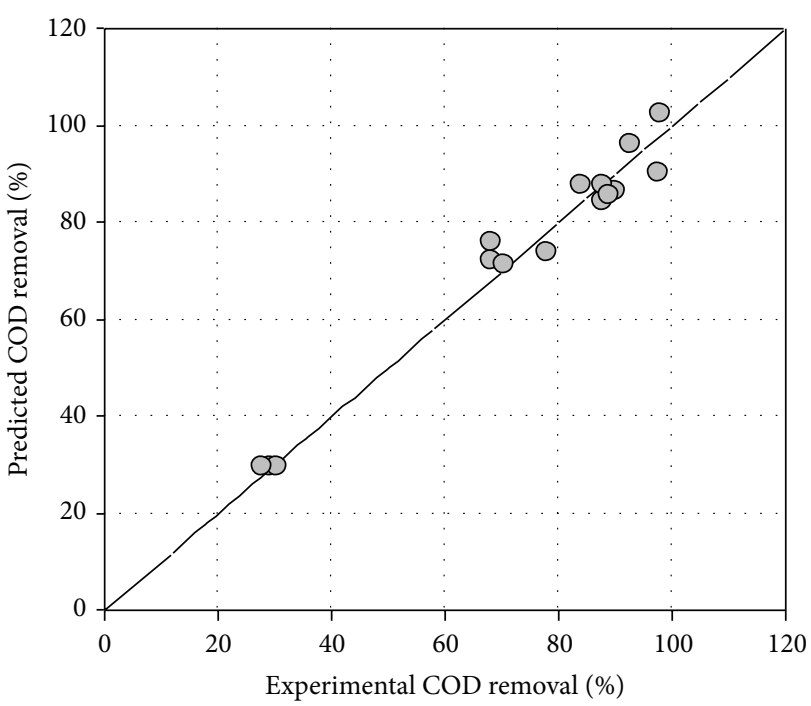

FIgURE 2: Predicted versus experimental data for COD removal (\%) $\left(R^{2}=0.97\right)$.

$P$ value is lower than 0.01 , the model is acceptable [17]. ANOVA of the tested model (Tables 5 and 6 ) indicated that the model is significant since the $F$-model is 19.94 and has a low probability value $(P>F=0.002105)$.

The response (COD removal, \%) surfaces of two-dimensional contour plots and three-dimensional curves, generated by MATLAB 7.0, notably illustrate the relations between two interacting factors with the response $(\eta)$, while the third factor was kept constant at zero. Figure 3 shows the response under the variable concentrations of $\mathrm{Fe}^{2+}$ and $\mathrm{H}_{2} \mathrm{O}_{2}$. It demonstrates a considerable enhancement of COD removal (\%) when the $\mathrm{H}_{2} \mathrm{O}_{2}$ concentration was increased. However, at higher concentrations of $\mathrm{H}_{2} \mathrm{O}_{2}$ the reduction rate was negatively affected. This trend (the decline of \% COD removal with $\mathrm{H}_{2} \mathrm{O}_{2}$ concentrations higher than the optimum) is more evident when the iron concentration is low. Thus, an increase in the concentration of this reagent does not grant a continuing improvement to the COD removal efficiency of the treated wastewater. Similarly, the reduction percentage of COD demonstrated an increase with increasing $\mathrm{Fe}^{2+}$ concentration to a certain point after which it became slower. This indicates that there is an optimal dosage for both $\mathrm{Fe}^{2+}$ and $\mathrm{H}_{2} \mathrm{O}_{2}$ concentrations. Similarly, the $3 \mathrm{D}$ surface and the corresponding contour plot in Figure 4 show that the combination of $\mathrm{Fe}^{2+}$ concentration and $\mathrm{pH}$ has a significant effect on COD removal. The detrimental effect of higher $\mathrm{H}_{2} \mathrm{O}_{2}$ concentration is probably due to both autodecomposition of $\mathrm{H}_{2} \mathrm{O}_{2}$ into oxygen and water and the recombination of $\mathrm{OH}$ radicals [21]. If either $\mathrm{H}_{2} \mathrm{O}_{2}$ or $\mathrm{Fe}^{2+}$ is not present in optimal dosage, it will scavenge $\mathrm{OH}$ radicals and reduce their available amount in solution [19]. Figure 5 demonstrates that the increase in $\mathrm{pH}$ with the increase in the $\mathrm{H}_{2} \mathrm{O}_{2}$ concentration enhanced the rate of COD removal in a certain zone, beyond which less reduction of COD is observed. Therefore, optimising the sensitive parameters 


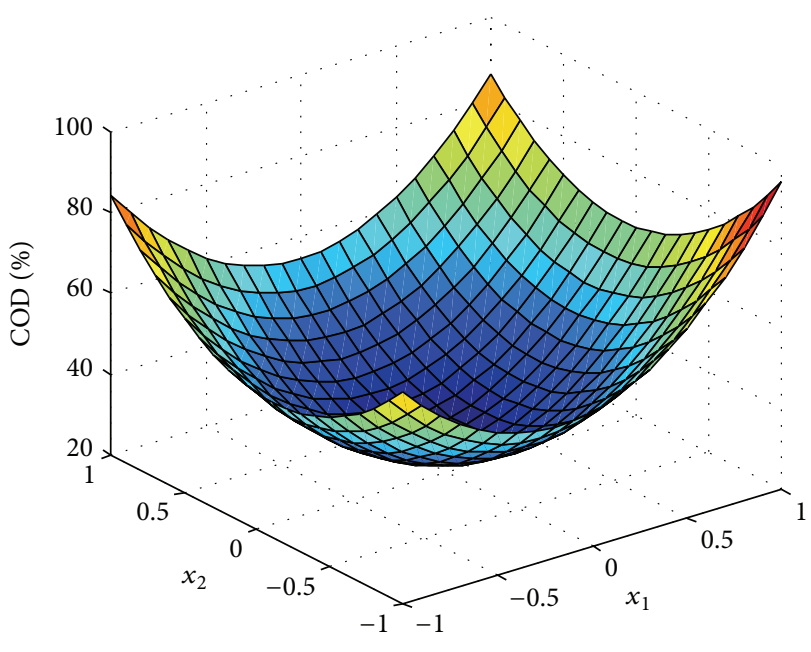

(a)

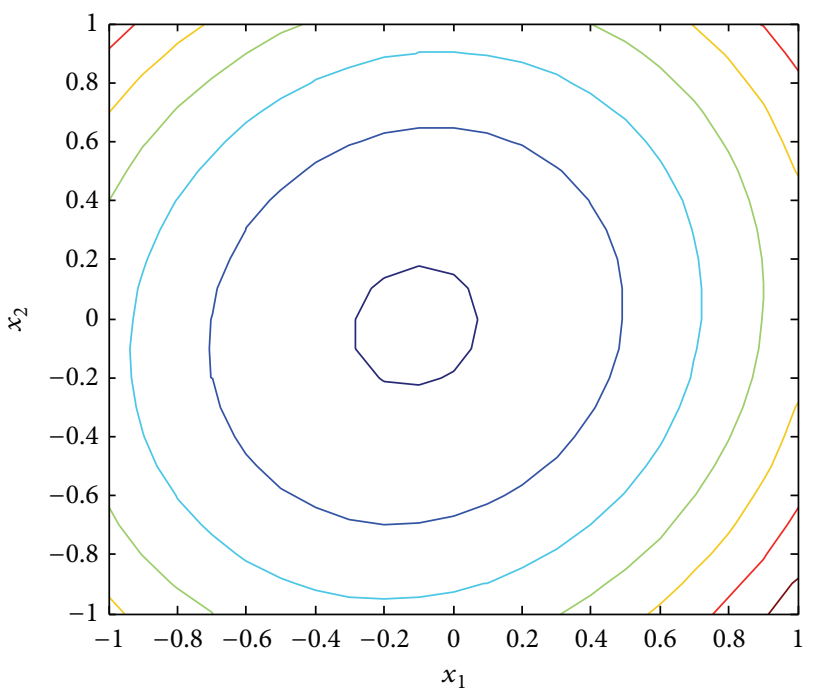

(b)

Figure 3: 3D surface and contour plot of response surface curve for COD removal showing interaction between (a) $\mathrm{Fe}^{2+}$ and (b) $\mathrm{H}_{2} \mathrm{O}_{2}$.

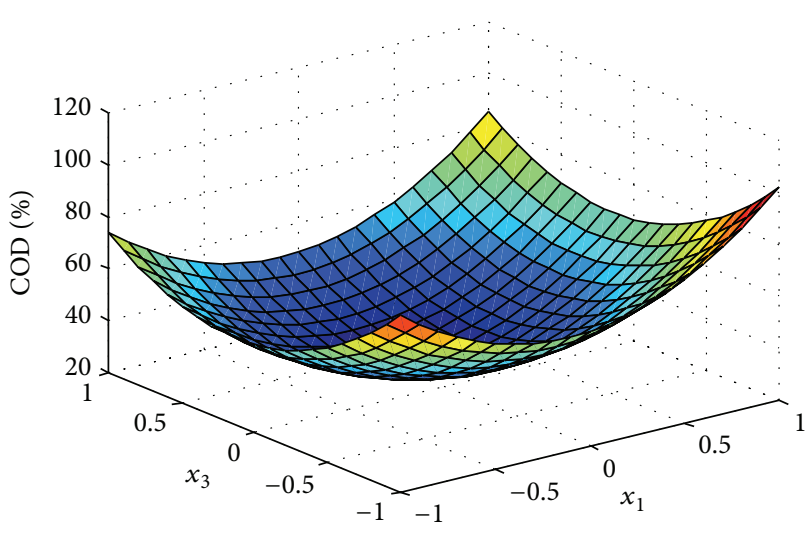

(a)

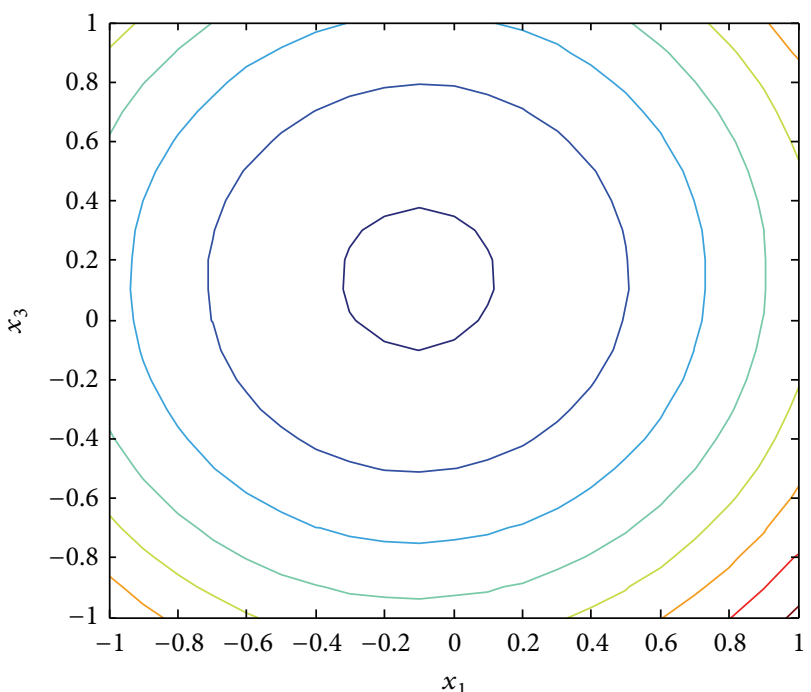

(b)

FIGURE 4: 3D surface and contour plot of response surface curve for COD removal showing interaction between $\mathrm{Fe}^{2+}$ and $\mathrm{pH}$.

TABLE 5: ANOVA coefficient of regression and $t$ checking ${ }^{1}$.

\begin{tabular}{lcccc}
\hline Variable & Standard deviation & $T$ & $P>t$ & Coefficient \\
\hline$X_{1}$ & 2.405956 & 2.691238 & 0.043235 & 0.812987 \\
$X_{2}$ & 2.405956 & 0.249381 & 0.023985 & -7.6 \\
$X_{3}$ & 2.405956 & -3.20039 & 0.000331 & 30.825 \\
$X_{1} X_{1}$ & 3.541472 & 8.704009 & 0.166922 & -5.5 \\
$X_{1} X_{2}$ & 3.402536 & -1.61644 & 0.834259 & -0.75 \\
$X_{1} X_{3}$ & 3.402536 & -0.22042 & 0.000945 & 24.625 \\
$X_{2} X_{2}$ & 3.541472 & 6.953324 & 0.609995 & 1.85 \\
$X_{2} X_{3}$ & 3.402536 & 0.543712 & 0.000599 & 27.175 \\
$X_{3} X_{3}$ & 3.541472 & 7.673364 & &
\end{tabular}

${ }^{1} R^{2}$ : coefficient of determination; values were 0.97 for COD percent removal. 
TABLE 6: Analysis of variance (ANOVA) for the RSM model.

\begin{tabular}{|c|c|c|c|c|c|}
\hline Source & Degree of freedom (df) & Sum of squares (SS) & Mean squares (MS) & $F$ statistics & $P>F$ \\
\hline Model & 9 & 8309.248 & 923.2498 & 19.93673 & 0.002105 \\
\hline Linear & 3 & 812.605 & 812.605 & 17.547452 & 0.880207 \\
\hline Square & 3 & 3631.609 & 3631.609 & 78.42124 & 1.001512 \\
\hline Interaction & 3 & 4979.369 & 4979.369 & 107.52485 & 0.611539 \\
\hline Error & 5 & 231.545 & 46.309 & & \\
\hline Total & 14 & 8540.793 & & & \\
\hline
\end{tabular}

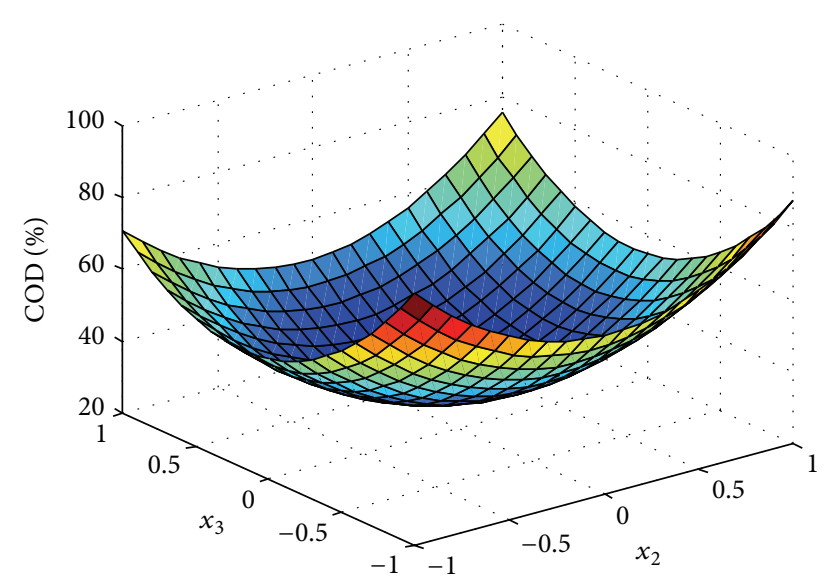

(a)

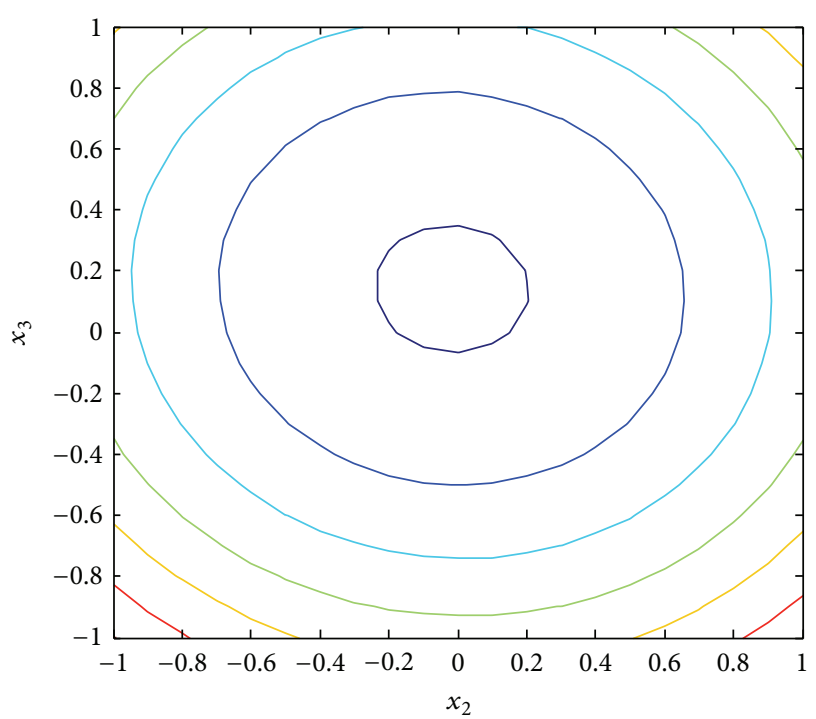

(b)

FIGURE 5: 3D surface and contour plot of response surface curve for COD removal showing interaction between $\mathrm{H}_{2} \mathrm{O}_{2}$ and $\mathrm{pH}$.

( $\mathrm{Fe}^{2+}, \mathrm{H}_{2} \mathrm{O}_{2}$ concentrations, and $\mathrm{pH}$ ) was conducted to achieve the highest COD removal for the system.

3.3. Optimization Analysis. Using the method of experimental factorial design and response surface analysis, the optimal conditions for COD removal percentage by photo-Fenton's reagent can be determined. Optimum values of the selected
TABLE 7: Optimum values of the process parameters for maximum efficiency.

\begin{tabular}{lc}
\hline Parameter & Optimum value \\
\hline$\eta(\mathrm{COD}$ reduction rate, \%) & 91.7 \\
$\mathrm{Fe}^{2+}(\mathrm{mg} / \mathrm{L})$ & 48.4 \\
$\mathrm{H}_{2} \mathrm{O}_{2}(\mathrm{mg} / \mathrm{L})$ & 403.9 \\
$\mathrm{pH}$ & 3.5 \\
\hline
\end{tabular}

variables can be achieved by solving the regression equation (using MATHEMATICA software (V 5.2)). The optimum values of the test variables in-coded were as follows: $\mathrm{Fe}^{+2}$ dosage, $x_{1}=48.4 \mathrm{mg} / \mathrm{L}, \mathrm{H}_{2} \mathrm{O}_{2}$ dosage, $x_{2}=403.9 \mathrm{mg} / \mathrm{L}$, and $\mathrm{pH}, x_{3}=3.5$, while the predicted response was $91.7 \%$. According to the relation between $\delta_{i}$ and $x_{i}$, the natural values of the test variables are shown in Table 7. This finding is in agreement with the previous observation of Tony et al. [16] and Kositzi et al. [22] for the treatment of wastewater.

The optimal molar ratio $\mathrm{H}_{2} \mathrm{O}_{2}: \mathrm{Fe}^{+2}$ in the present study is $12: 1$; hence, the hydrogen peroxide is in excess. This optimal molar ratio compares well with the molar ratio of 11:1 given by Tang and Huang [23] for 2,4-dichlorophenol degradation.

Increasing $\mathrm{H}_{2} \mathrm{O}_{2}$ concentration results in the generation of additional reaction intermediates $\left({ }^{\circ} \mathrm{OH}\right)$ radicals which enhances the degradation process. However, at higher peroxide concentrations, the excess hydrogen peroxide can act as an ${ }^{\circ} \mathrm{OH}$ scavenger, forming $\mathrm{HO}^{\circ}{ }_{2}$, which is also a free radical produced in situ from the $\mathrm{H}_{2} \mathrm{O}_{2}$ but is a less reactive oxidizing agent and therefore has a longer life time than the ${ }^{\circ} \mathrm{OH}$ and the result is a reduction in the overall reaction rate [24, 25]. Moreover, iron concentrations above the optimal value result in reduced process performance because more species of iron ions are produced rather than the more useful ${ }^{\circ} \mathrm{OH}$ radicals. This finding is in agreement with the previous observation of Kositzi et al. [22].

The recommended $\mathrm{pH}$ value in this investigation of $\mathrm{pH}$ 3.5 is well in agreement with the suggested value of 3.0 by Fongsatitkul et al. [26] in the treatment of wastewater from textile industry. These findings clearly suggest that the optimal ratio of the reagent concentration and the $\mathrm{pH}$ value vary in accordance with the type of the substance to be treated.

3.4. Verification of the Results. In order to validate the efficiency of the model, three additional experiments using 
TABLE 8: Predicted and experimental values for the responses at optimum conditions.

\begin{tabular}{lc}
\hline Type of value & COD reduction, \% \\
\hline Predicted & 91.7 \\
Experimental & 93.4 \\
\hline
\end{tabular}

these optimum operating conditions were conducted. The duplicate experiments yielded an average COD removal percentage of $97 \%$. The predicted COD reduction efficiencies (\%) via (2) are jointly shown in Table 8 . A good agreement of the data between the experimental and the predicted can be obtained with regression coefficient $R^{2}$ value of 0.97 (plotting is shown in Table 2). Thus, it is reasonable to believe that the polynomial model (2) is a reliable model to describe the Fenton reaction behaviour in the wastewater treatment.

\section{Conclusion}

Results from the present study have demonstrated the effectiveness of the application of photo-Fenton reagent $\left(\mathrm{Fe}^{2+} / \mathrm{H}_{2} \mathrm{O}_{2}\right)$ in the treatment of wastewater delivered from car wash centres. The response surface methodology for optimising such process parameters was applied. This experimental design methodology was shown to be a valuable tool in optimizing the process, which could be satisfied with the minimum number of experiments. The three statistical variables, $\mathrm{Fe}^{2+}, \mathrm{H}_{2} \mathrm{O}_{2}$ concentrations, and $\mathrm{pH}$, showed optimal values, giving maximum percentage COD reduction that reached $97 \%$ in treating such car washing water used in the study. The optimal molar ratio of $\mathrm{H}_{2} \mathrm{O}_{2}: \mathrm{Fe}^{2+}$ was found to be $12: 1$ and the optimum $\mathrm{pH}$ was 3.5 . These findings are comparable to the literature. This demonstrates the usefulness and effectiveness of the Fenton reagent as an advanced technique for the treatment process.

\section{Conflict of Interests}

The authors declare that there is no conflict of interests regarding the publication of this paper.

\section{References}

[1] J. Smith, "Public survey used to estimate pollutant loads in Maryland. Technical Note 73," Watershed Prtection Tecnology, vol. 2, no. 2, pp. 361-363, 1996.

[2] N. Hardwick, Lake Sammamish Watershed Water Quality Survey, King County Water and Land Resources Division, Seattle, Wash, USA, 1997.

[3] National Environmental Education Training Foundation (NEETF), National Report Card on Environmental Knowledge, Attitudes and Behaviors: Seventh Annual Roper Survey of Adult Americans, National Environmental Education Training Foundation, Washington, DC, USA, 1999.

[4] K. Madwar and H. Tarazi, "Desalination techniques for industrial wastewater reuse," Desalination, vol. 152, no. 1-3, pp. 325332, 2003.
[5] M. F. Abdel-Sabour, H. I. Abdel-Shafy, and A. R. Mohamed, "Plant yield production and heavy metals accumulation as affected by sewage sludge application on desert soil," Sustainable Water Management, vol. 1, pp. 27-31, 2005.

[6] I. Hua and M. R. Hoffmann, "Optimization of ultrasonic irradiation as an advanced oxidation technology," Environmental Science and Technology, vol. 31, no. 8, pp. 2237-2243, 1997.

[7] W. H. Glaze, Y. Lay, and J. W. Kang, "Advanced oxidation processes: a kinetic model for the oxidation of 1,2-dibromo-3chloropropane in water by the combination of hydrogen peroxide and UV radiation," Industrial and Engineering Chemistry Research, vol. 34, no. 7, pp. 2314-2323, 1995.

[8] B. Ensing, F. Buda, and E. J. Baerends, "Fenton-like chemistry in water: oxidation catalysis by $\mathrm{Fe}(\mathrm{III})$ and $\mathrm{H}_{2} \mathrm{O}_{2}$," Journal of Physical Chemistry A, vol. 107, no. 30, pp. 5722-5731, 2003.

[9] R. F. P. Nogueira, A. G. Trovó, and W. C. Paterlini, "Evaluation of the combined solar $\mathrm{TiO}_{2}$ /photo-Fenton process using multivariate analysis," Water Science and Technology, vol. 49, no. 4, pp. 195-200, 2004.

[10] M. A. Tony, P. J. Purcell, Y. Q. Zhao, A. M. Tayeb, and M. F. ElSherbiny, "Photo-catalytic degradation of an oil-water emulsion using the photo-fenton treatment process: effects and statistical optimization," Journal of Environmental Science and Health A, vol. 44, no. 2, pp. 179-187, 2009.

[11] E. Evgenidou, K. Fytianos, and I. Poulios, "Semiconductorsensitized photodegradation of dichlorvos in water using $\mathrm{TiO}_{2}$ and $\mathrm{ZnO}$ as catalysts," Applied Catalysis B: Environmental, vol. 59, no. 1-2, pp. 81-89, 2005.

[12] C. Petrier, M. Micolle, G. Merlin, J. L. Luche, and G. Reverdy, "Characteristics of pentachlorophenate degradation in aqueous solution by means of ultrasound," Environmental Science \& Technology, vol. 26, no. 8, pp. 1639-1642, 1992.

[13] Y. Xiao, G. Wang, H. Liu et al., "Treatment of H-acid wastewater by photo-fenton reagent combined with a biotreatment process: a study on optimum conditions of pretreatment by a photofenton process," Bulletin of Environmental Contamination and Toxicology, vol. 69, no. 3, pp. 430-435, 2002.

[14] J. Sanz, J. I. Lombrana, A. M. de Luis, M. Ortueta, and F. Varona, "Microwave and Fentons reagent oxidation of wastewater," Environmental Chemistry Letters, vol. 50, pp. 1-45, 2003.

[15] F. J. Rivas, F. J. Beltrán, O. Gimeno, and J. Frades, “Treatment of olive oil mill wastewater by Fenton's reagent," Journal of Agricultural and Food Chemistry, vol. 49, no. 4, pp. 1873-1880, 2001.

[16] M. A. Tony, P. J. Purcell, Y. Q. Zhao, and M. F. El-Sherbiny, "Evaluating the photo-catalytic application of Fenton's reagent augmented with $\mathrm{TiO}_{2}$ and $\mathrm{ZnO}$ for the mineralization of an oilwater emulsion," Journal of Environmental Science and Health A, vol. 44, no. 5, pp. 488-493, 2009.

[17] SAS, SAS/STAT User's Guide, SAS Institute, Cary, NC, USA, 1990.

[18] F. Torrades, M. Pérez, H. D. Mansilla, and J. Peral, "Experimental design of Fenton and photo-Fenton reactions for the treatment of cellulose bleaching effluents," Chemosphere, vol. 53, no. 10, pp. 1211-1220, 2003.

[19] C. T. Benatti, C. R. G. Tavares, and T. A. Guedes, "Optimization of Fenton's oxidation of chemical laboratory wastewaters using the response surface methodology," Journal of Environmental Management, vol. 80, no. 1, pp. 66-74, 2006.

[20] D. C. Montgomery, Design and Analysis of Experiments, John Wiley \& Sons, New York, NY, USA, 1991. 
[21] V. Sarria, S. Kenfack, O. Guillod, and C. Pulgarin, "An innovative coupled solar-biological system at field pilot scale for the treatment of biorecalcitrant pollutants," Journal of Photochemistry and Photobiology A: Chemistry, vol. 159, no. 1, pp. 89-99, 2003.

[22] M. Kositzi, I. Poulios, S. Malato, J. Caceres, and A. Campos, "Solar photocatalytic treatment of synthetic municipal wastewater," Water Research, vol. 38, no. 5, pp. 1147-1154, 2004.

[23] W. Z. Tang and C. P. Huang, "2,4-dichlorophenol oxidation kinetics by Fenton's reagent," Environmental Technology, vol. 17, no. 12, pp. 1371-1378, 1996.

[24] W. Chu, "Modeling the quantum yields of herbicide 2,4-D decay in $\mathrm{UV} / \mathrm{H}_{2} \mathrm{O}_{2}$ process," Chemosphere, vol. 44, no. 5, pp. 935-941, 2001.

[25] M. Litorja and B. Ruscic, "A photoionization study of the hydroperoxyl radical, $\mathrm{HO}_{2}$, and hydrogen peroxide, $\mathrm{H}_{2} \mathrm{O}_{2}$," Journal of Electron Spectroscopy and Related Phenomena, vol. 97, no. 1-2, pp. 131-146, 1998.

[26] P. Fongsatitkul, P. Elefsiniotis, A. Yamasmit, and N. Yamasmit, "Use of sequencing batch reactors and Fenton's reagent to treat a wastewater from a textile industry," Biochemical Engineering Journal, vol. 21, no. 3, pp. 213-220, 2004. 

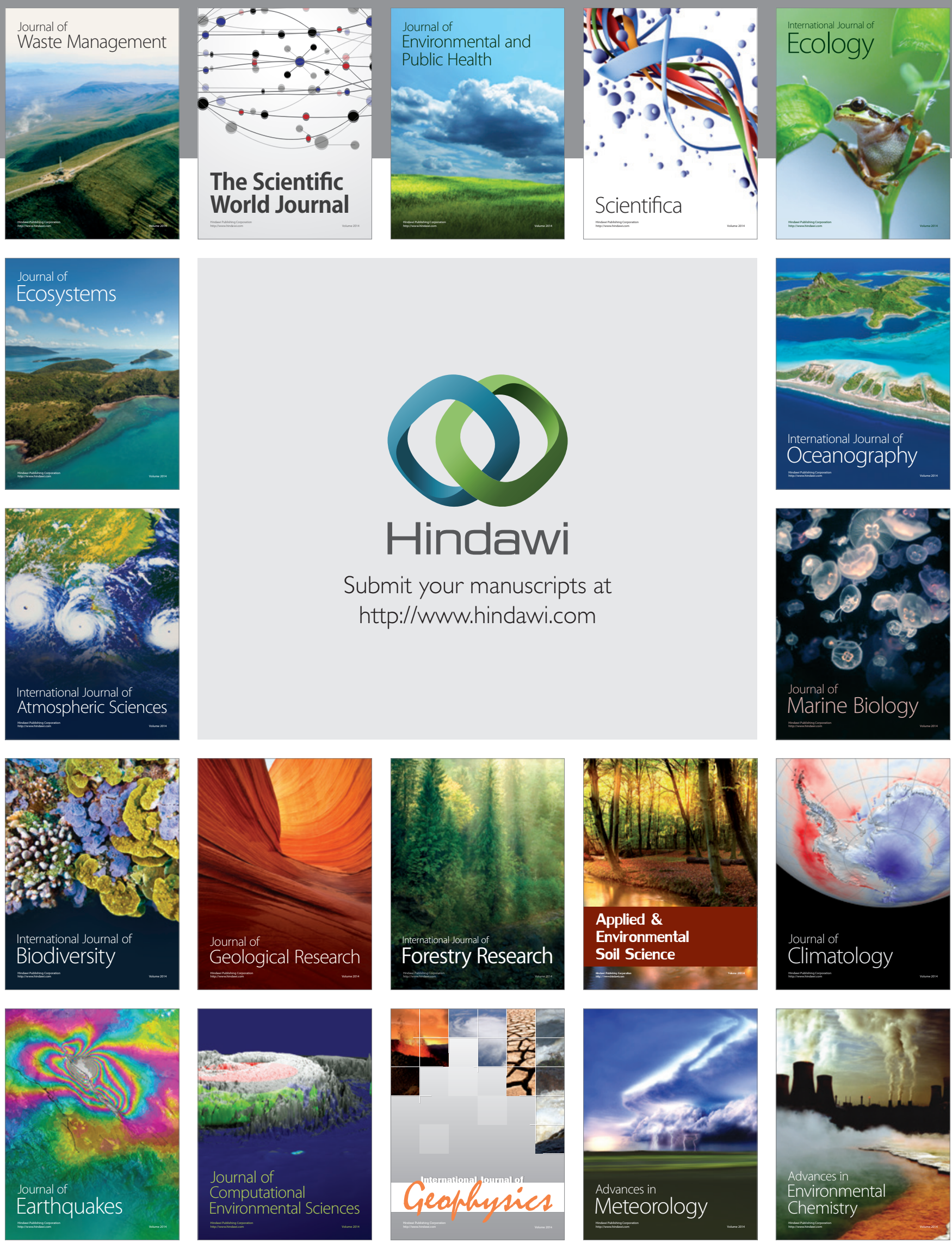